\title{
DECOMPOSIÇÃO TÉRMICA DE PELLETS DE MADEIRA POR TGA
}

\author{
D. P. GARCIA ${ }^{1 *}$, J. C. CARASCHI ${ }^{2}$ e G. VENTORIM ${ }^{2}$ \\ ${ }^{1}$ UNESP-FEG: Campus de Guaratinguetá/SP \\ ${ }^{2}$ UNESP: Campus de Itapeva/SP \\ pelletsdemadeira@gmail.com*
}

Artigo submetido em dezembro/2015 e aceito em janeiro/2016

DOI: $10.15628 /$ holos.2016.3886

\section{RESUMO}

A utilização dos pellets de madeira para a geração de energia térmica está se difundindo no Brasil e a análise termogravimétrica tem sido amplamente aplicada para o estudo da decomposição da madeira e seus principais componentes como a celulose, as hemiceluloses e a lignina. $O$ objetivo deste trabalho foi investigar o comportamento térmico de quatro diferentes amostras de pellets de madeira, em condições não isotérmicas, por meio das análises termogravimétricas TGA. Os ensaios foram conduzidos desde a temperatura ambiente até $500^{\circ} \mathrm{C}$, com taxa de aquecimento de $20^{\circ} \mathrm{C} / \mathrm{min}$, em atmosfera inerte de gás nitrogênio, com fluxo de 100 $\mathrm{mL} / \mathrm{min}$. Os termogramas mostraram três estágios de decomposição: o primeiro, atribuído à evaporação da água e dos materiais voláteis; o segundo, refere-se à decomposição da holocelulose na pirólise ativa; e o terceiro, atribuído a decomposição da lignina na pirólise passiva. Além disso, conclui-se que a maior decomposição térmica ocorreu na faixa de temperatura compreendida entre $250^{\circ} \mathrm{C}$ e $400^{\circ} \mathrm{C}$, com perdas superiores a $60,8 \%$ da massa inicial do biocombustível.

PALAVRAS-CHAVE: Pellets de Madeira, Biomassa, Pirólise da Madeira, Termogravimetria por TGA.

\section{THERMAL DECOMPOSITION OF WOOD PELLETS BY TGA}

\begin{abstract}
The use of wood pellets for generating thermal energy is spreading in Brazil and thermogravimetric analysis has been widely applied to study the decomposition of wood and its main components such as cellulose, hemicellulose and lignin. The objective of this study was to investigate the thermal behavior of four different samples of wood pellets in non-isothermal conditions by means of thermogravimetric analysis TGA. Assays were performed from room temperature to $500^{\circ} \mathrm{C}$ with a heating rate of $20^{\circ} \mathrm{C} / \mathrm{min}$ in an inert atmosphere of nitrogen gas with a
\end{abstract}

flow of $100 \mathrm{~mL} / \mathrm{min}$. The thermograms showed three decomposition stages: first, assigned to the evaporation of water and volatile materials; the second, refers to the decomposition of the active holocellulose pyrolysis; and third, attributed to the decomposition of lignin pyrolysis passive. Furthermore, it is concluded that most decomposed in the temperature range between $250^{\circ} \mathrm{C}$ and $400^{\circ} \mathrm{C}$, with greater than $60.8 \%$ of the initial mass of the biofuels losses.

KEYWORDS: Wood Pellets, Biomass, Pyrolysis, Thermogravimetric by TGA. 


\section{INTRODUÇÃO}

Pellets de madeira (Figura 1) são biocombustíveis sólidos que podem ser produzidos a partir de resíduos da indústria madeireira como a serragem e a maravalha de madeira. São compactados e densos e com baixo teor de umidade, de 8 a 10\%, permitindo elevada eficiência na combustão. Sua geometria regular e cilíndrica permite boa fluidez, comportando-se como se fosse líquido, e isso facilita automatizar processos comerciais e industriais de queima do produto. Além disso, é um produto natural de fácil manuseio, ocupa pouco espaço na estocagem e tem elevada densidade energética (GARCIA et al., 2013).

A utilização dos pellets de madeira tem baixo impacto ao meio ambiente, pois é uma forma de energia de baixo carbono, ou seja, grande parte do gás $\mathrm{CO}_{2}$, emitido na sua queima, pode ser recuperado no crescimento da planta. Na Europa e na Ásia é apontado como alternativa aos combustíveis fósseis, relacionando seu uso à diminuição das emissões dos gases do efeito estufa. No Brasil, os dados divergem quanto à produção de pellets: Lamers et al. (2012), em sua pesquisa sobre o mercado internacional dos combustíveis sólidos, estimaram a produção de pellets de madeira em 20 mil t/ano, em 2010; a Associação Brasileira dos Produtores de Florestas Plantadas - ABRAF (2013), no entanto, informou que o Brasil produziu, neste mesmo período, 47 mil t/ano.

De acordo com a Associação Brasileira das Indústrias de Pellets (ABIPEL, 2013), em geral, as indústrias que produzem esse biocombustível são de pequeno porte e tem baixa capacidade produtiva com pequenos equipamentos que produzem de 0,5 a 4,0 t/h. Além disso, questões tecnológicas como a baixa eficiência, baixo volume e o alto custo da produção limita a sua utilização ao mercado interno e, por isso, poucas indústrias produtoras no país estão exportandoo. A biomassa florestal mais utilizada para a produção dos pellets de madeira é o Pinus (coníferas - softwood) em função da grande disponibilidade destes resíduos vindos das indústrias madeireiras que fabricam móveis no Centro-Sul do Brasil. Problemas com custos logísticos de transporte dessa matéria prima para a fábrica e do produto já acabado, apontados por Tavares e Tavares (2015), também dificultam uma participação mais expressiva do país no comércio internacional.

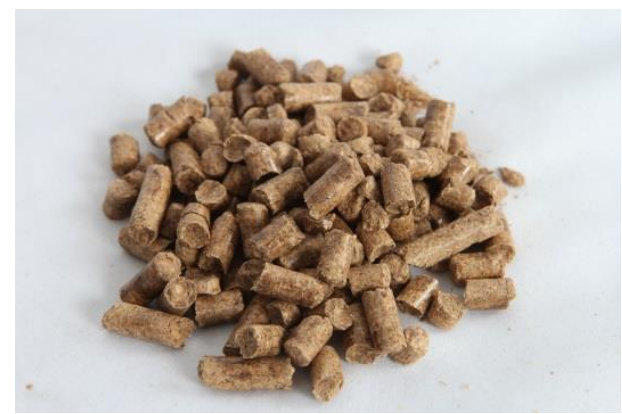

Figura 1: Pellets de madeira: $\phi=6,0 \mathrm{~mm}$; Comprimento $=20,0-40,0 \mathrm{~mm}$

Este estudo é importante porque as características dos pellets de madeira e a temperatura da decomposição são essenciais para modelar a combustão em processos industriais (YORULMAZ; ATIMTAY, 2009). Além disso, o conhecimento da decomposição térmica é fundamental para o 
controle de rendimento do biocombustível. Embora existam diferenças significativas nas condições de operação, a termogravimetria fornece uma ferramenta poderosa para realizar estudos preliminares sobre a decomposição térmica de combustíveis sólidos (LÓPEZ-GONZÁLEZ et al., 2013).

As análises termogravimétricas (TGA) e sua derivada (DTG) são as técnicas mais utilizadas para investigar e comparar os eventos térmicos durante a pirólise de pequenas amostras de combustível e medir as variações de massa durante o aquecimento. Esta técnica permite interpretar o comportamento dos pellets de madeira durante a sua decomposição, determinar a estabilidade térmica do material, além de fornecer informações de quais faixas de temperatura ela é mais pronunciada (SANTOS et al., 2012).

A TGA pode ser realizada em atmosfera oxidante (oxigênio), podendo-se chegar à combustão restando somente cinzas no final do processo, mas também pode ser realizada em atmosfera inerte $\left(\mathrm{N}_{2}\right.$ ou $\left.\mathrm{CO}_{2}\right)$, sem combustão, mas com desprendimento de umidade e voláteis, além de possíveis reações químicas e físicas, como foi o processo de carbonização da madeira estudado por Pinheiro; Figueiredo; Seye (2006).

A pirólise de biomassa florestal (analisada pela técnica experimental da TGA) tem sido estudada por muitos pesquisadores como Dietenberger (2002); Mohan et al. (2006); Jelemenský et al. (2010); Liodakis et al. (2002); Hu et al. (2004); Blasi (2008); Grønli et al. (2002); Pizzarro et al. (2013), Sebio-Puñal et al. (2012) e os principais eventos químicos são descritos nessas literaturas: decomposição da celulose entre $300^{\circ} \mathrm{C}$ e $400^{\circ} \mathrm{C}$; decomposição das hemiceluloses entre $200^{\circ} \mathrm{C} \mathrm{e}$ $300^{\circ} \mathrm{C}$; decomposição da lignina entre $280^{\circ} \mathrm{C}$ a $500^{\circ} \mathrm{C}$.

Materiais lignocelulósicos são conhecidos por apresentarem diferentes perfis de decomposição, de acordo com a sua composição química, com a celulose apresentando maior estabilidade térmica do que as hemiceluloses e lignina (MOHAN et al., 2006). As hemiceluloses são os menos estáveis dos componentes da madeira, devido à presença de grupos acetil. A decomposição da lignina ocorre simultaneamente com as hemiceluloses e a celulose, na pirólise ativa e passiva, mas não apresenta picos característicos (BARTOCCl et al., 2012).

Neste mesmo sentido, Grønli et al. (2002) relataram que, durante o processo de decomposição térmica da biomassa lignocelulósica, a holocelulose (celulose + hemiceluloses) é decomposta primeiro, seguido pela lignina, a temperaturas mais elevadas. No processo de compactação dos resíduos lignocelulósicos para fabricar pellets, a lignina é a responsável pela coesão interna entre as partículas, provocada pelo calor na temperatura de transição vítrea, que a reorganiza entre as fibras, ligando-as naturalmente.

De acordo com Riegel et al. (2008), dados obtidos a partir de experimentos dinâmicos demonstraram que a temperatura na qual ocorre a principal reação de decomposição da madeira, entre $300^{\circ} \mathrm{C}$ e $450^{\circ} \mathrm{C}$, desloca-se em função das taxas de aquecimento aplicadas. Porém, pode-se observar também que a perda de água adsorvida (na primeira fase) ocorreu aproximadamente a uma mesma faixa de temperatura, independentemente se a taxa de aquecimento é $2^{\circ} \mathrm{C} / \mathrm{min}$ ou $50^{\circ} \mathrm{C} / \mathrm{min}$. 
Conforme apontado por Saddawi et al. (2010), a decomposição da biomassa florestal é um processo muito complexo em razão da ocorrência de grande número de reações e a natureza delas. A fase de transição da biomassa sólida para gasosa também aumentam a dificuldade e complicam a interpretação das análises, sobretudo quando modelos detalhados que lidam com o fenômeno de transporte entre as fases são utilizados. A avaliação da função de transferência de calor e massa entre as fases e a sua importância em todo o processo podem afetar, significativamente, os resultados.

De acordo com Zabaniotou et al. (2011), objetivando observar e compreender a decomposição térmica da biomassa florestal, vários modelos que utilizam um limitado, mas sucessivo, número de reações paralelas tem sido desenvolvido para descrever este processo, incluindo modelos que lidam apenas com a transformação química de uma fase para a outra. Outros, porém, consideram a biomassa como uma mistura de seus principais constituintes (celulose, hemiceluloses e lignina) e empregam as reações para a conversão química destes usando um modelo para a contabilização das reações das principais macromoléculas, a fim de descrever a decomposição térmica de cada um deles. Não há estudos termogravimétricos sobre os pellets de madeira produzidos no Brasil, por isso os estudos de TGA da madeira foram utilizados para comparações com os pellets de madeira.

Diante do exposto, o objetivo deste trabalho foi avaliar a decomposição térmica dos pellets de madeira, em condições não isotérmicas, por meio das análises termogravimétricas TGA e DTG.

\section{METODOLOGIA}

\subsection{Material Biológico}

Foram analisadas quatro procedências de pellets de madeira de três estados brasileiros: um de São Paulo (pellets P1-SP); dois do Paraná (pellets P2-PR e pellets P3-PR); e um de Santa Catarina (pellets $\mathrm{P} 4-\mathrm{SC}$ ). As amostras foram obtidas nos locais de venda e identificadas apenas por uma sigla, acompanhada pelo estado de origem, para evitar a promoção positiva ou negativa das marcas comerciais. Os biocombustíveis estavam em suas embalagens tradicionais e foram produzidos com subprodutos (serragem, maravalha e pó de serra) de indústrias madeireiras das regiões sul e sudeste do Brasil. A matéria-prima dos pellets P1-SP é a serragem de Eucalyptus e dos demais, Pinus. Não foi possível identificar, com precisão, o gênero nem a espécie porque o material reunido vem de diversas indústrias que beneficiam várias espécies ao mesmo tempo. As caracterizações iniciais destas amostras estão relacionadas na Tabela 1. Efetuaram-se análises imediatas das amostras moídas e peneiradas em 40/60 mesh, por meio de moinho de 1,5 kW tipo Willey, seguindo os procedimentos preconizados na norma NBR 8112 (ABNT, 1986), adaptada para pellets de madeira, com determinação dos teores de materiais voláteis, cinzas e carbono fixo, em base seca. Para as análises químicas de lignina e holocelulose utilizou-se a norma TAPPI T 211(TAPPI, 2000) e os extrativos totais foram determinados de acordo com a norma ABTCP M3 (ABTCP, 1974). $A$ extração foi feita em tolueno/etanol e água quente. Para o Poder Calorífico Superior (PCS), uma bomba calorimétrica isotérmica, marca IKA WORKS modelo C-5000, foi utilizada seguindo metodologia estabelecida na norma NBR 8633 (ABNT, 1984), que prescreve o método de determinação do PCS do carvão vegetal, adaptada para os pellets, que foram triturados antes das 
análises. Para teor de extrativos e de umidade realizou-se três repetições para cada amostra coletada e as demais, quatro.

\subsection{Análises termogravimétricas (TGA/DTG)}

As análises termogravimétricas foram realizadas no Laboratório de Materiais da Faculdade de Engenharia de Guaratinguetá (FEG/UNESP). A partir das curvas TGA/DTG, procederam-se as análises de perda de massa nos dois intervalos de temperatura: picos 1 e 2, faixa de temperatura de $25^{\circ} \mathrm{C}$ a $250^{\circ} \mathrm{C}$ e $250^{\circ} \mathrm{C}$ a $400^{\circ} \mathrm{C}$.

\subsection{Métodos}

A avaliação da porcentagem mássica, da temperatura de decomposição e das perdas de voláteis das amostras foram realizadas em um equipamento da Seiko, modelo TGA/DTA 6200 em atmosfera $\mathrm{N}_{2}$, com fluxo de $100 \mathrm{~mL} / \mathrm{min}$ e razão de aquecimento de $20^{\circ} \mathrm{C} / \mathrm{min}$, da temperatura ambiente até $500^{\circ} \mathrm{C}$. Esta razão de aquecimento foi escolhida por ser frequentemente usada por pesquisadores nas análises térmicas e, desta forma, os dados podem ser facilmente comparados na literatura. A massa utilizada em cada experimento foi de aproximadamente 10,0 mg e o método experimental utilizado, para avaliar as perdas de massa, foi o não isotérmico empregando um gradiente constante de temperatura.

\subsection{Análise Estatística}

As médias obtidas, de cada uma das análises, foram submetidas à análise de variância (ANOVA) e sendo o valor de F expressivo, aplicou-se o teste Tukey a $5 \%$ de significância, com o objetivo de identificar quais valores médios diferiram significativamente entre si. A avaliação da correlação entre as variáveis foi realizada pelo coeficiente de Pearson. Os dados foram processados com o auxílio do software estatístico XLSTAT (2015).

\section{RESULTADOS E DISCUSSÃO}

Como podemos observar na Tabela 1, as amostras de pellets de madeira foram caracterizadas por análise imediata, análise química e térmica com delineamento inteiramente casualizado, com quatro tratamentos (tipos de pellets) e três repetições (por amostra), totalizando 12 unidades amostrais. Com relação a variável lignina e carbono fixo, verificou-se que os diferentes tipos de pellets de madeira, não apresentaram efeitos estatisticamente significativos, quando comparadas entre si, pelo teste de Tukey ao nível de $5 \%$ de probabilidade, ao contrário dos demais. 
Tabela 1: Caracterização inicial das amostras de pellets de madeira (Média \pm Desvio Padrão). Média seguida pela mesma letra, na linha, não diferem entre si pelo teste de Tukey conduzido a $\mathbf{5 \%}$ de significância.

\begin{tabular}{lcccc}
\hline \multicolumn{1}{c}{ Pellets de madeira } & P1-SP & P2-PR & P3-PR & P4-SC \\
\hline \multicolumn{1}{c}{ Análise Imediata } & \multicolumn{2}{c}{$\%$ massa } \\
Carbono fixo & $15,63 \pm 0,27 \mathrm{a}$ & $14,70 \pm 0,12 \mathrm{a}$ & $15,42 \pm 0,87 \mathrm{a}$ & $14,56 \pm 0,46 \mathrm{a}$ \\
Teor de Voláteis & $83,45 \pm 0,26 \mathrm{a}$ & $84,98 \pm 0,11 \mathrm{bc}$ & $84,00 \pm 0,87 \mathrm{ab}$ & $84,90 \pm 0,47 \mathrm{bc}$ \\
Teor de Cinzas & $0,93 \pm 0,01 \mathrm{a}$ & $0,33 \pm 0,02 \mathrm{~b}$ & $0,58 \pm 0,02 \mathrm{c}$ & $0,54 \pm 0,01 \mathrm{~d}$ \\
Teor de Umidade & $10,25 \pm 0,06 \mathrm{a}$ & $6,76 \pm 0,21 \mathrm{~b}$ & $7,78 \pm 0,07 \mathrm{c}$ & $8,55 \pm 0,09 \mathrm{~d}$ \\
\multicolumn{1}{c}{ Análises Químicas } & & \multicolumn{2}{c}{$\%$ massa } & \\
Extrativos & $3,95 \pm 0,13 \mathrm{a}$ & $6,54 \pm 0,30 \mathrm{~b}$ & $8,38 \pm 0,20 \mathrm{c}$ & $5,58 \pm 0,30 \mathrm{~d}$ \\
Holocelulose & $67,25 \pm 0,97 \mathrm{a}$ & $65,94 \pm 0,85 \mathrm{ab}$ & $64,53 \pm 0,66 \mathrm{bc}$ & $66,03 \pm 0,95 \mathrm{ac}$ \\
Lignina & $29,31 \pm 1,05 \mathrm{a}$ & $28,02 \pm 1,08 \mathrm{a}$ & $26,79 \pm 0,57 \mathrm{a}$ & $28,42 \pm 1,15 \mathrm{a}$ \\
$\quad$ Análise Térmica & & \multicolumn{2}{c}{$\mathrm{MJ} / \mathrm{kg}$} & $18,71 \pm 0,11 \mathrm{a}$ \\
\hline
\end{tabular}

Teores de lignina, extrativos e cinzas são fundamentais para a seleção de materiais lignocelulósicos para a produção de energia, pois influenciam diretamente o poder calorífico dos materiais, seja positiva ou negativamente. Já quanto ao teor de umidade, há uma forte correlação negativa com o PCS (PAULA et al., 2011; DEMIRBAS, 2001). O maior PCS apresentado pelos pellets P2-PR pode ser explicado por esses fatores. Neste estudo, utilizando-se do coeficiente de Pearson, encontrou-se correlação negativa forte entre PCS $\times$ Umidade $(R=-0,81)$, PCS $\times$ Lignina $(R=-0,74)$, PCS $\times$ Cinzas $(R=-0,67)$. Em contrapartida, correlação negativa fraca entre PCS $x$ Voláteis $(R=-$ $0,34)$ e PCS $x$ Holocelulose $(R=-0,40)$.

Teores de cinzas das amostras de pellets apresentaram valores entre 0,33 - 0,93\% e estão próximos daqueles informados por Obernberger e Thek (2010), que encontraram teores entre 0,4 - 1,3\%. Segundo esses autores, as coníferas, geralmente apresentam menores teores de cinzas do que as folhosas e isso explica o maior teor de cinzas dos pellets P1-SP, produzidos a partir de serragem de Eucalyptus.

Na Figura 2 (a, b, c, d), apresentam-se, respectivamente, os termogramas da decomposição térmica dos pellets de madeira, referentes às análises de TGA e sua derivada DTG, obtidas em atmosfera inerte de $\mathrm{N}_{2}$, a uma taxa constante de aquecimento de $20^{\circ} \mathrm{C} /$ minuto. A decomposição térmica das macromoléculas naturais, em atmosfera de nitrogênio, produz muitas reações complexas que ocorrem em intervalos de tempo muito próximos. Durante a decomposição, pequenas moléculas, como extrativos e componentes voláteis, entram em ignição e são eliminadas (BIANCHI et al., 2010). Além disso, na termogravimetria não isotérmica, os dados de perda de massa são função da temperatura e do gradiente empregado no experimento e a formação de compostos com maior ou menor estabilidade térmica está ligada diretamente ao tipo de arranjo estrutural e a quantidade dos componentes básicos de cada espécie de madeira, como por exemplo, a maior presença de holocelulose e lignina. 

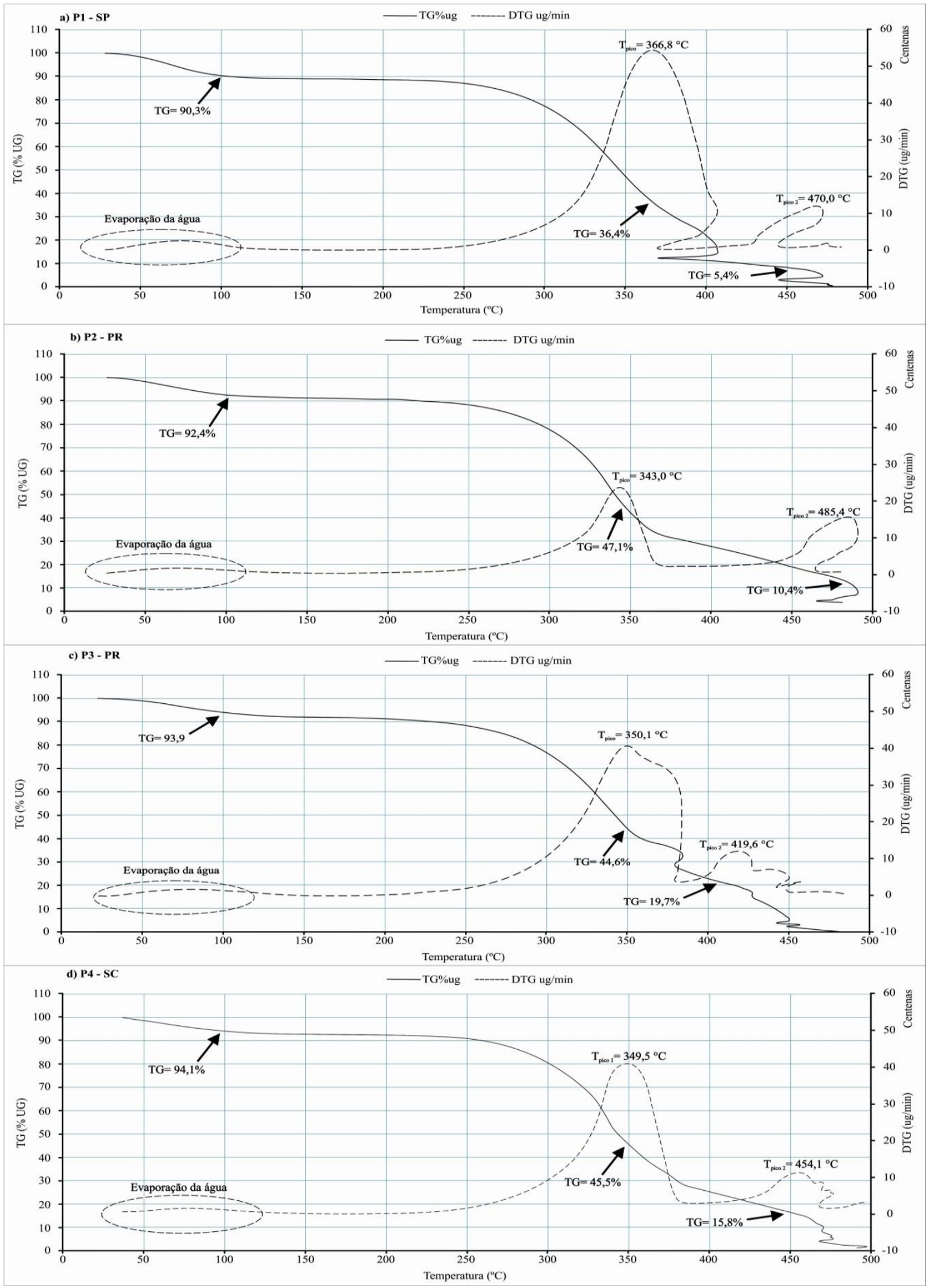

Figura 2 - Termogramas TGA / DTG dos pellets em atmosfera de $\mathrm{N}_{2}$, fluxo de $100 \mathrm{~mL} / \mathrm{min}$.

Observa-se a partir destes termogramas, que o comportamento de todos os pellets de madeira (P1-SP, P2-PR, P3-PR e P4-SC) durante a decomposição térmica foram semelhantes. As amostras apresentaram três etapas evidentes de decomposição: a primeira, a temperaturas em torno de $100^{\circ} \mathrm{C}$, pode ser atribuída à perda de água por dessorção (considerado evento térmico de 
origem física, pois não há perda de massa do material); a segunda, a temperaturas mais altas, que são atribuídas à decomposição dos pellets de madeira, cujos componentes principais são celulose, hemiceluloses e lignina; e a terceira, nas temperaturas acima de $419^{\circ} \mathrm{C}$, é atribuída a decomposição da lignina remanescente que, nos estudos de Riegel et al. (2008), iniciaram a temperaturas mais baixas e continuaram ocorrendo até $500^{\circ} \mathrm{C}$. Raad et al. (2006), estudaram a carbonização do Eucalyptus urophylla e cloeziana, e encontraram picos de temperatura para a decomposição da celulose, hemiceluloses e lignina de $360^{\circ} \mathrm{C}, 310^{\circ} \mathrm{C}, 430^{\circ} \mathrm{C}$, respectivamente, destacando a alta estabilidade térmica da lignina em comparação com a holocelulose.

As inflexões observadas na curva DTG são decorrentes das etapas que envolvem variação de massa na curva termogravimétrica TGA. O ponto de maior intensidade em cada uma das inflexões da curva DTG corresponde à temperatura em que a respectiva reação está ocorrendo mais rapidamente, ou seja, é a temperatura de pico. A ausência da variação de massa na curva TG origina um patamar horizontal na curva DTG, uma vez que nesta condição a derivada $\mathrm{dm} / \mathrm{dT}=0 \mathrm{Na}$ primeira etapa da decomposição térmica, pode-se atribuir ao primeiro ponto de temperatura, em que $\mathrm{dm} / \mathrm{d} T \neq 0$, como sendo aquela que o combustível avaliado deixa de ser termicamente estável sob as condições experimentais utilizadas.

A perda de massa inicial dos pellets $\mathrm{P} 1-\mathrm{SP}=9,7 \%, \mathrm{P} 2-\mathrm{PR}=7,6 \%, \mathrm{P} 3-\mathrm{PR}=6,1 \%$ e $\mathrm{P} 4-\mathrm{SC}=5,9 \%$, evidenciada nas temperaturas próximas de $100^{\circ} \mathrm{C}$, apontadas nas setas da Figura 2, decorrentes da evaporação de água, estão relacionadas aos teores de umidade do material. Assim, a maior perda de massa inicial foi dos pellets P1-SP, por ter o maior teor de umidade inicial, $10,25 \%$.

Assim como Pereira et al. (2013), a partir de temperaturas próximas a $400^{\circ} \mathrm{C}$, verifica-se que a degradação térmica dos pellets tornou-se menor, correspondendo, principalmente, à degradação de lignina posto que, nessa temperatura, a celulose e as hemiceluloses, componentes químicos em maior proporção na madeira, já foram degradadas.

Este estudo apresenta limitações impostas pela grande variedade de opções do ensaio de TGA quanto a taxa de aquecimento, fluxo do gás e matéria-prima, sendo difícil dimensionar as interferências dessas opções nos resultados.

O patamar horizontal na curva DTG indica ausência de variação de massa na curva TG, e isso ocorreu para todos os pellets avaliados, até aproximadamente $250^{\circ} \mathrm{C}$, indicando que o biocombustível apresentou-se estável (nestas condições experimentais) até nesta faixa de temperatura. Atribui-se a esta etapa, além da dessorção da água, possíveis perdas de substâncias voláteis e extrativos presentes no biocombustível (Tabela 1), pois nenhuma outra variação de massa significativa foi evidenciada entre $100^{\circ} \mathrm{C}$ e $250^{\circ} \mathrm{C}$. Outros dois eventos importantes, pico $1 \mathrm{e}$ 2, foram observados nas curvas TG/DTG a partir desta temperatura, os quais se referem à decomposição térmica dos pellets de madeira, conforme mostrados na Tabela 2.

Para a faixa de temperatura de $250-400^{\circ} \mathrm{C}$, principal região de decomposição e onde ela foi mais acentuada, ocorreu a pirólise ativa das amostras que apresentaram perfis de curvas de perda de massa com maiores percentuais de P1-SP>P4-SC>P3-PR $>$ P2-PR, respectivamente de $71,5 \%>65,6 \%>65,2 \%>60,8 \%$, observados na Tabela 2 . Pode-se inferir que isso é consequência do maior teor de holocelulose dos P1-SP e P4-SC, conforme também foi verificado por Santos et al. 
(2012) e Bianchi et al. (2010). A intensidade da decomposição nesta faixa de temperatura pode ser explicada, de acordo com Loppinet-Serani et al. (2011), pela quantidade total dos principais componentes da madeira (holocelulose e lignina). Riegel et al. (2008) informaram que, nesta faixa de temperatura de até $400^{\circ} \mathrm{C}$, ocorre intensa cisão de cadeias poliméricas (despolimerização) da celulose, acompanhada do início da decomposição da lignina, sendo a decomposição da celulose o processo dominante nesta etapa. Ainda nesta faixa de temperatura, observa-se que o P2-SP apresentou a menor perda de massa total $(60,8 \%)$, e portanto, mais estável termicamente em relação aos demais.

Observa-se pela Figura 2, que o ponto de maior intensidade, em cada uma das inflexões da curva DTG, corresponde à temperatura em que a respectiva reação está ocorrendo mais rapidamente, ou seja, temperaturas de pico. Essa velocidade máxima de perda de massa para os pellets, que ocorreu entre $343^{\circ} \mathrm{C}$ a $366,8^{\circ} \mathrm{C}$, está próximo daqueles encontrados por Bianchi et al. (2010), que obteve $360^{\circ} \mathrm{C}$ para a Garapeira (folhosa) e $375^{\circ} \mathrm{C}$ para o Pinus (conífera). Diferentes autores, como Mohan et al. (2006); Jelemenský et al. (2010); Hu et al. (2004); Blasi (2008); Pizzarro et al. (2013), também comprovaram a decomposição da celulose e das hemiceluloses nestas faixas de temperaturas. Por outro lado, Skreiberg et al. (2011), estudando o comportamento térmico da madeira de demolição, informaram que a holocelulose decompõe-se em fases separadas de celulose e hemiceluloses, uma independente da outra, e a lignina a uma taxa mais lenta e mais ampla. Segundo o autor, a pirólise das hemiceluloses iniciou a uma temperatura acima de $200^{\circ} \mathrm{Ce}$ a celulose começou a decompor-se acima de $300^{\circ} \mathrm{C}$. A lignina começou a decompor-se na mesma temperatura das hemiceluloses e mostrou gradual perda de massa até os $500^{\circ} \mathrm{C}$.

Assim como os resultados de Pereira et al. (2013), não foi detectada faixa específica de degradação da lignina por esta ocorrer em larga amplitude de temperatura. Além disso, sua temperatura final de degradação costumeiramente é superior à temperatura final avaliada $\left(450^{\circ} \mathrm{C}\right)$, havendo sobreposição das faixas.

Tabela 2 - Dados da pirólise dos pellets de madeira a partir das curvas da Figura 1

\begin{tabular}{cccc}
\hline Amostra & Eventos & Temperatura $\left({ }^{\circ} \mathrm{C}\right)$ & Perda de massa Total (\%) \\
\hline \multirow{3}{*}{ P1-SP } & Dessorção & 250,0 & 12,8 \\
& Faixa & $250-400$ & 71,3 \\
& Pico 1 & 366,8 & 63,6 \\
& Pico 2 & 470,0 & 94,6 \\
\hline P2-PR & Dessorção & 250,0 & 11,9 \\
& Faixa & $250-400$ & 60,8 \\
& Pico 1 & 343,0 & 52,9 \\
& Pico 2 & 485,4 & 89,6 \\
\hline \multirow{2}{*}{ P3-PR } & Dessorção & 250,0 & 11,6 \\
& Faixa & $250-400$ & 65,2 \\
& Pico 1 & 350,1 & 55,4 \\
& Pico 2 & 419,6 & 80,2 \\
\hline & Dessorção & 250,0 & 9,1 \\
& Faixa & $250-400$ & 65,6 \\
& Pico 1 & 349,5 & 54,2 \\
& Pico 2 & 454,1 & 84,2 \\
\hline
\end{tabular}


Bartocci et al. (2012), num estudo termogravimétrico do processo de pirólise do Poplar wood (populus L.) em atmosfera inerte de $N_{2}$, e Jelemenský et al. (2010), relataram três regiões de decomposição bem clara: evaporação da água, pirólise ativa e passiva. O processo principal da pirólise ocorreu até $377^{\circ} \mathrm{C}$ e o secundário seguiu até $470^{\circ} \mathrm{C}$. Na região principal ocorrem a pirólise ativa, com dois picos de decomposição, relativos às hemiceluloses e celulose. A lignina se decompõe em ambas as regiões, porém sem picos característicos de temperatura. Desta forma podemos inferir que os picos 1 e 2 de temperatura, observados nos termogramas da Figura 2, são decorrentes da pirólise ativa e passiva, das hemiceluloses e celulose, respectivamente. Neste mesmo sentido, Zabaniotou et al. (2011), chamaram o segundo estágio da decomposição de cavacos de madeira de "pirólise passiva" e o atribui a decomposição da celulose. Já Lópes-González et al. (2013), estudando os principais componentes da biomassa lignocelulósica, mostraram que a lignina é o componente mais estável termicamente, devido a sua estrutura polimérica tridimensional, e sua decomposição ocorreu numa faixa que vai de $146^{\circ} \mathrm{C}$ até $550^{\circ} \mathrm{C}$, passando por ampla faixa de temperaturas e com baixa taxa de decomposição.

Assim como alguns autores (SKREIBERG et al., 2011; LÓPES-GONZÁLEZ et al., 2013, ZABANIOTOU et al., 2011 e JELEMENSKÝ et al., 2010) que perceberam a decomposição da lignina se estender à temperatura de $500^{\circ} \mathrm{C}$, neste estudo dos pellets, a pirólise desses biocombustíveis sólidos também ocorreram a temperaturas inferiores a esta. Lei et al. (2012) e Loppinet-Serani et al. (2011), estudando a pirólise de pellets produzidos a partir de resíduos de Douglas Fir (uma conífera), também observaram a decomposição deles em temperaturas inferiores a esta. Então, podemos atribuir à lignina residual a região final, cauda plana horizontal, da curva DTG, de temperatura mais alta, que se prolonga depois do pico 2 até o fim do processo de decomposição, com temperaturas inferiores a $500^{\circ} \mathrm{C}$.

Quanto a maior decomposição dos pellets P1-SP, mostrados na Figura 2 (TG=36,4\% e $\mathrm{T}=366,8^{\circ} \mathrm{C}$ ), em comparação com os outros, pode ser explicada pelas características químicas da espécie Eucalyptus: superior teor de carbono, holocelulose e lignina, observado na Tabela 1. Estudos posteriores de análises termogravimétricas devem contemplar a correlação e a influência da lignina, antes e depois do processo de compactação, a fim de se buscar relação entre a transição vítrea e a alta temperatura no processo de produção dos pellets de madeira.

\section{CONCLUSÃO}

Neste trabalho, a decomposição térmica dos pellets de madeira e seus principais componentes químicos (celulose, hemiceluloses e lignina) foram estudados, em atmosfera inerte de nitrogênio. De acordo com os resultados das análises termogravimétricas, TGA e DTG, concluise que:

$\rightarrow$ A decomposição do biocombustível pellets de madeira ocorreu em três estágios de perda de massa: o primeiro estágio, é atribuído a evaporação da água e materiais voláteis (até $250^{\circ} \mathrm{C}$ ); o segundo, e mais pronunciado estágio, da pirólise ativa $\left(250-400^{\circ} \mathrm{C}\right)$ decompondo principalmente, a holocelulose; e o último, da pirólise passiva, representado pela lenta e constante decomposição da lignina podendo chegar até $500^{\circ} \mathrm{C}$. 
$\rightarrow$ A maior decomposição térmica dos pellets de madeira avaliados ocorreu na faixa de temperatura compreendida entre $250-400^{\circ} \mathrm{C}$ (pirólise ativa), durante a qual se obtiveram perdas superiores a $60,8 \%$ da massa inicial do biocombustível.

$\rightarrow$ Os pellets P2-PR possuem as melhores características térmicas para um biocombustível sólido com baixo teor de cinzas $(0,33 \%)$, baixo teor de umidade $(6,76 \%)$ e maior PCS $(19,48 \mathrm{MJ} / \mathrm{kg})$.

\section{REFERÊNCIAS}

1. ASSOCIAÇÃO BRASILEIRA DE PRODUTORES DE FLORESTAS PLANTADAS (ABRAF). Anuário Estatístico: ano base 2012. 148p. Pöyry Silviconsult Engenharia Ltda. Brasília: 2013.

2. ASSOCIAÇÃO BRASILEIRA DAS INDÚSTRIAS DE PELLETS (ABIPEL). Mapa de pellets no Brasil 2013. Disponível em: <http://www.abipel.com.br>. Acesso em: 20 de out. 2013.

3. ASSOCIAÇÃO BRASILEIRA DE NORMAS TÉCNICAS (ABNT). NBR 8112: Carvão vegetal - Análise Imediata (Adaptada para pellets). Rio de Janeiro, 1986.

4. ASSOCIAÇÃO BRASILEIRA DE NORMAS TÉCNICAS (ABNT). NBR 8633: Carvão vegetalDeterminação do poder calorífico superior (Adaptada para pellets). Rio de Janeiro, 1984.

5. ASSOCIAÇÃO BRASILEIRA TÉCNICA DE CELULOSE E PAPEL (ABTCP). M3/69: Métodos de ensaio - Extrativos Totais. São Paulo, 1974.

6. BARTOCCI, P.; SLOPIECKA, K.; FANTOZZI, F. Thermogravimetric analysis and kinetic study of poplar wood pyrolysis. Applied Energy, v.97, p. 491-497, 2012.

7. BIANCHI, O. et al. Avaliação da degradação não-isotérmica de madeira através de termogravimetria-TGA. Polímeros, v. 20, n. especial, p.395-400, 2010.

8. BLASI, C. D. Modeling chemical and physical processes of wood and biomass pyrolysis. Progress in Energy and Combustion Science, v.34, n.1, p.47-90, 2008.

9. DEMIRBAS, A. Relationships between lignin contents and heating values of biomass. Energy Conversion and Management, v.42, n.2, p. 183-188, 2001.

10. DIETENBERGER, M. Update for combustion properties of wood components. Fire and Materials, v. 26, n. 6, p.255-267, 2002.

11. GARCIA, D. P.; CARASCHI, J. C.; VENTORIM, G. Caracterização energética de pellets de madeira. Revista da Madeira, v. 135, p. 14-18, 2013.

12. GRØNLI, M.G.; VÁRHEGYI, G.; BLASI, C.D. Thermogravimetric Analysis and Devolatilization Kinetics of Wood. Industrial \& Engineering Chemistry Research, v.41, n.17, p.4201-4208, 2002.

13. HU, H. et al. Nonisothermal Catalytic Liquefaction of Corn Stalk in Subcritical and Supercritical Water. Energy Fuels, v.18, p.90-96, 2004.

14. JELEMENSKÝ. L.; GAŠPAROVIČ, L.; KOREŇOVÁ, Z. Kinetic study of wood chips decomposition by TGA. Chemical Papers, v.64, n. 2, p.174-181, 2010.

15. LAMERS, P. et al. Developments in international solid biofuel trade - An analysis of volumes policies and market factors. Renewable Sust. Energy Reviews, v.16, n.5, p.3176-3179, 2012. 
16. LEI, H. et al. Biofuel production and kinetics analysis for microwave pyrolysis of Douglas fir sawdust pellet. Journal Analytic Applied Pyrolysis, v.94, p.163-169, 2012.

17. LIODAKIS, S.; BAKIRTZIS, D.; LOIS, E. TG and auto ignition studies on forest fuels. Journal of Thermal Analysis and Calorimetry, v.69, n. 2, p.519-528, 2002.

18. LÓPEZ-GONZÁLEZ, D. et al. Thermogravimetric-mass spectrometric analysis on combustion of lignocellulosic. Bioresource Technology, v.143, p.562-574, 2013.

19. LOPPINET-SERANI, A. et al. Thermogravimetric analysis as a new method to determine the lignocellulosic composition of biomass. Biomass and Bioenergy, v.35, n. 1, p.298-307, 2011.

20. MOHAN, D.; PITTMAN, C.U.; STEELE, P.H. Pyrolysis of wood / biomass for bio-oil: a critical review. Energy Fuels, v.20, n.3, p.848-849, 2006.

21. OBERnBerger, I.; THEK, G. The Pellet Handbook: The production and thermal utilization of biomass pellets. London: Earthscan, 2010. 593p.

22. PAULA, L. E. R. et al. Characterization of residues from plant biomass for use in energy generation. Cerne, v.17, n.2, p.237-246, 2011.

23. PEREIRA, B.L.C. et al. Estudo da degradação térmica da madeira de Eucalyptus através de termogravimetria e calorimetria. Revista Árvore, v.37, n.3, p.567-576, 2013.

24. PINHEIRO, P. C. C.; FIGUEIREDO, F. J.; SEYE, O. Influência da temperatura e da taxa de aquecimento da carbonização nas propriedades do carvão vegetal. Biomassa e Energia, v.2, n. 2, p.159-168, 2006.

25. PIZARRO, C. et al. Biomass proximate analysis using thermogravimetry. Bioresource Technology, v. 139, p.1-4, 2013.

26. RAAD, T. J.; PINHEIRO, P. C. C.; YOSHIDA, M.I. Equação geral de mecanismos cinéticos da carbonização do Eucalyptus spp. Cerne, v.12, n.2, p.93-106, 2006.

27. RIEGEL, I. et al. Análise Termogravimétrica da Pirólise da Acácia-Negra (Acacia mearnsii de Wild.) Cultivada no Rio Grande do Sul, Brasil. Revista Árvore, v. 32, n. 3, p.533-543, 2008.

28. SADDAWI, A. et al. Kinetics of the thermal decomposition of biomass. Energy Fuels, v. 24, p.1274-1282, 2010.

29. SANTOS, R. C. et al. Análise Termogravimétrica em clones de eucalipto como subsídio para a produção de carvão vegetal. Cerne, v. 18, n. 1, p.143-151, 2012.

30. SEBIO-PUÑAL, T. et al. Thermogravimetric analysis of wood, holocelulose and lignin from five wood species. Journal of Thermal Analysis and Calorimetry, v.109, n.3, p.1163-1167, 2012.

31. SKREIBERG, A. et al. TGA and macro-TGA characterization of biomass fuels and fuel mixtures. Fuel, v. 90, n.6, p.2182-2197, 2011.

32. TECHNICAL ASSOCIATION OF THE PULP AND PAPER INDUSTRY (TAPPI). Ash in wood and pulp. T 211 om-93. Standard Method. Atlanta, 2000.

33. TAVARES, S. R. L.; TAVARES, M. A. M. E. Perspectivas para a participação do brasil no mercado internacional de pellets. HOLOS, [S.I.], v. 5, p. 292-306, 2015.

34. YORULMAZ, S. Y.; ATIMAY, A. T. Investigation of combustion kinetics of treated and untreated waste wood samples with thermogravimetry. Fuel Processing Technology, v. 90, p.939-946, 2009. 
35. XLSTAT (2015). Statistical Software versão 2014.5. Paris, France: Addinsoft SARL.

36. ZABANIOTOU, A. et al. Thermal degradation studies and kinetic modeling of cardoon (Cynara cardunculus) pyrolysis using thermogravimetric analysis. Bioresource Technology, v.102, p.6230-6238, 2011. 